YAK 378:1

ББК $74.58+87.25$

DOI 10.22394/1682-2358-2020-2-76-85

V.A. Ruchin, Head of the Chinese Centre of Yuri Gasarin Saratov State Technical University

A.V. Ruchin, sociologist at NORMTSMI of Yuri Gagarin Saratov State Technical University

\section{EDUCATION SYSTEMS IN CONTEMPORARY SOCIETY: SOCIAL AND PHILOSOPHICAL ANALYSIS}

The state of society, connected with the consequences of internal radical changes, is analyzed. It is intensified by external factors, which caused the revision of conceptual bases in the established social-philosophical approach to the institute of education. Firstly, the sources of revision of the ideal of social order formed in the Soviet period and the image of an ideal citizen are studied. The rapid socio-cultural dynamics that led to the editing of the system of values and the transitory management of the social structure are assessed.

Key words and word-combinations. Russian civilization, education sphere, philosophy of education, triad of the ideal, phenomenon, institution.
B.A. Ручин, руководитель Китайского центра Саратовского государственного технического университета имени Гагарина Ю.А. (email:r-vl@yandex.ru)

A.В. Ручин, сочиолог НОРмЦмИ СГТу имени Гагарина Ю.А. (email: ralexey@inbox.ru)

\section{СИСТЕМЫ ОБРАЗОВАНИЯ B COВРЕМЕННОМ ОБЩЕСТВЕ: СОЦИААЬНО- ФИ ОСОФСКИЙ АНААИЗ}

\begin{abstract}
Аннотация. Анализируется состояние общества, связанное с последствиями внутренних радикальных перемен, усиленное внешними факторами, породившими пересмотр концептуальных основ в сложившемся социально-философском подходе к институту образования. Исследуются истоки ревизии сформированного в советское время идеала социального порядка, а вместе с ним и образа идеального гражданина. Оценивается стремительная социокультурная динамика, которая привела к редактированию системы ценностей, транзитивности управления социальной структурой.

Ключевые слова и словосочетания: российская цивилизация, сфера образования, философия образования, триада идеального, феномен, институт.
\end{abstract}

P ном обществе - вопрос особенно важный в ситуации «масштабных социальных, эко-

* Исследование выполнено при финансовой поддержке РФФИ в рамках научного проекта № 20-311-70023.

76 Bulletin of the Volga Region Institute of Administration • 2020. Vol. 20. № 2 
номических, технологических задач», - подчеркнул В.В. Путин в Послании Федеральному Собранию РФ от 15 января 2020 г. Транзитивность российского общества состоит в том, что оно за короткий исторический промежуток стремительно перешио от жесткой эгалитарной модели к хаосу этапа первоначального накопмения капитала, жизни «без предела», затем к некоторой стабилизации и, наконец, к возрождению традиционных ценностей в условиях прессинга миберализма.

Актуальность темы определена запросом российского общества на перемены. «Һюди хотят развития и сами стремятся двигаться впереА в профессии, знаниях, в достижении благополучия, готовы брать на себя ответственность за конкретные дела» [1]. Аля ответа на поставленный вопрос обратимся к анализу многомерного образовательного Аискурса.

Рискогенность образовательного пространства [2, с. 16] требует монографичности его исследования в целях преодоления важного обстоятельства - отягощенности образовательного Аискурса противоречивостью научных направлений, в которых просматривается стремление «перетянуть одеяно на себя», разделить сферу образования на сегменты, а самого человека на удобные Амя изучения «предметы». В связи с этим жизненно важно понять, образование - это рыночная услуга или фактор созидания человеческого начала в самом человеке, установить связь кичного и общественного, а также выявить потенџиал межкультурного диалога в условиях глобализации $[2$, с. 95-101].

Сегодня российское образование функщионирует в условиях расщепценного цемеполагания, осознать которое можно только через оттенки и смыслы, фиксированные в сложившейся социокультурной матрице сферы образования. В Федеральном законе от 29 декабря 2012 г. № 273 «Об образовании в Российской Федераџии» трактовка образования преАстает как «единый цеменаправменный процесс воспитания и обучения» (п. 1 ст. 2). Признается общественная значимость образования как бкага, констатируется результат в виде совокупности приобретаемых знаний, умений, навыков, ценностных установок. Кумьтурный контекст развития человека в связи с удовлетворением его образовательных потребностей и интересов (п. 1 ст. 2) описан неполно. Федеральный закон регулирует обшественные отношения, возникающие в сфере образования по поводу получения знаний, прежде всего с точки зрения равного доступа к ним различных категорий граждан.

Воспитание в существуюшей трактовке ориентировано «на развитие и самоопределение мичности на основе социокультурных, духовно-нравственных ценностей и принятых в обществе правил и норм поведения» (п. 2 ст. 2]. КАючевые слова «развитие мичности», «принятые в обществе џенности» недостаточно ясно раскрывают смысл. Не до конца ясно, о каких социокультурных ценностях идет речь и на каких принџипах согласовываются интересы человека, семьи, общества, государства. Требует также разъяснения, как «социальное» Аолжно сочетаться с «культурным» в условиях большого города или малого насеменного пункта, страны в цемом или национальной республики, 
в частности. Если декларируется «социокультурный», следовательно, особый. Это значит, речь Аолжна иАти о культурном коде, исторически привязанном к цивилизации. Необходимо пояснить также, в чем этот код состоит Аля отдельных этносов и всего народа? На наш взгляд, при этом обойден мобилизационный, идеологический аспект. В результате нет полного ответа на вопрос, что подразумевается поА направлением развития общества в духовнонравственном смысле?

Понятие «обучение» в данном Федеральном законе трактуется как «цеменаправленный проџесс организаџии деятельности обучающихся по овмадению знаниями, умениями, навыками и компетенџией...» (п. 3 ст. 2). ОАнако не понятно, кому принадлежит приоритетная роль, а вместе с ней и ответственность за результаты образовательной деятельности? Понятие «система образования» сформулировано как порядок, создающий условия «Аля непрерывного образования посреАством реализации основных образовательных программ и различных дополнительных образовательных программ» (п. 7 ст. 10). Следовательно, система образования - это необходимый набор образовательных стандартов, образовательных учреждений, информационных ресурсов, участников учебно-воспитательного проџесса. Требуют разъяснения и отличия понятия «система образования» от упомянутого в тексте Закона, но не раскрытого по существу понятия «сфера образования». Если система образования - интеграция, то каким образом консолидируются ценностно-ориентированные факторы? Значит ки это, что процесс консолидаџии ценностей в рамках повседневной жизни не Ао конца разрешен, или он закреплен за сферой образования? Налиџо чисто технологический подхоА к образованию и приоритет знаний наА воспитанием.

Сегодня выдемено позитивистское отношение к образованию, декмаративно обоснованное гуманистической позицией к главному объекту деятельности системы образования - Человеку разумному, априори нуждающемуся в разнообразных знаниях. Такое обращение к понятиям «гуманистический» и «гуманизм» можно рассматривать как спорное и противоречивое [3] .

ОАнако фимософский подхоА к образованию построен иначе и берет свое начало из истории обращения к данному феномену, который, по мнению М. Хайдеггера, через слово отражкает сущее [4, с. 93], и в этом контексте «образование» есть категория, обозначающая глубокий смысл этого феномена. Соответственно, образование есть категория, обнаруживающая и обозначающая смысл бытия сущего. В связи с этим образование можно интерпретировать как наличие сушего с Авух позиџий: образование в «широком» и образование в «узком» смысле.

Под образованием в широком [5] смысле понимается масштабное взаимодействие участников образовательного проџесса, где «широкий» смысм включает исторический контекст, выражающий ведущие тенденџии соџиокультурного развития народа и его общественного устройства. Такое устройство обцадает опредеменной закономерностью, имманентно связанной с национальным менталитетом. В понятии «образование» соединяются сущ-

78 Bulletin of the Volga Region Institute of Administration • 2020. Vol. 20. № 2 
ность человека: его архетипические особенности, цивилизационная специфика освоения и преобразования природной среды и общества. Кроме того, образование - это бесконечный мир идей, господствующих в данном типе цивилизации, представляющей собой калейдоскопичность, многослойность потенциальных вариантов соџиокультурной ситуаџии [6] .

Образование в узком [5] смысме есть субъективный мир мичности, сфера внутренних идей, скрепленных волевыми усилиями. По существу, это субъективный, опредемяющий будущее «мирок» [7, с. 761], трактуемый как внутреннее бытие человека. В этом внутреннем бытии субъективность есть главный фактор мировоззренческих установок, включающий оџенку предметного мира. Селекџия приоритетных представлений, преАлагаемых соџиумом, осуществляется человеком сугубо мично, на основе самобытности кичности, ее проявления через взаимосвязь объективного и субъективного.

Внутреннее бытие человека, его объективно-субъективная деятельность перманентно находится в состоянии экзистенциальной неопределенности, трансформирующейся в ключевой фактор повседневности - рискогенность [8]. Опасность рисков на фоне новых вызовов соџиума бесконечно погружает человека в глубокие переживания, связанные с жизненным выбором, необходимостью обновления воззрений, а следовательно, требует дополнительных волевых усилий на базе определенных знаний.

Сущность человека заключена в рациональности его волевых усилий, направленных на реализацию мичных стратегий. Образование в узком смысле Аля человека есть «возрастание» к гуманности [9, с. 286-288], преодоление природного, Авижение от единичного к «всеобщему» [10, с. 356]. Развитие образованности и преодоление «образованщины» позволяет достичь власти наА миром. По существу образование - это не столько обучение, сколько совершенствование духовных качеств человека, его отказ от мичного, эгоистичного ради всеобщего.

Фицософский анализ позволяет поднять концепт «образование» до масштаба соџиального явления, когда изучение феномена «образование» преАполагает переход от его утилитарной оценки к философскому осмыслению. Это позволяет увидеть проџесс становления человека в культурном пространстве, объединенном главной ценностью той или иной цивилизации [11, с. 429]. Социокультурное пространство определяет ценностную ориентацию человека и следование правикам идентичности интерпретированной определенной могикой образования [12, с. 142-149; 13].

Стремление человека к возвышенному образу, мибо поднимает общество на нравственную вершину, кибо низвергает, когда человек отмежевывается от идеального образа [14, с. 359]. Если забыть об этом, то обыденность, как некультивируемые растения, стремительно забивает свободное дяя развития образовательное пространство.

Начало акта образования - это преодоление неопределенности индивидуального сознания посредством рефлексии, где достижение определенности осушествцяется актом переоџенки самого себя. Внутренний диалог сориентирован на внешний ценностный мир, культурную среду, и от того, как она 
будет задана и от ее заданности образованием в широком смысле зависит общественный идеал, к которому стремится человек.

Образование - не только учебный процесс или профессиональное обучение, но в определенном смысле предназначение, то есть подготовка человека, мишенная практических целей [15], стремление к нравственному образцу. Не создавая в обществе культурный образ, мы обрекаем молодое поколение на хаотичное создание образцов, то есть на создание суррогатов. Следовательно, вначале человек формируется и только затем обучается.

Философский поАхоА к образованию в духе традищии русской культуры стремление к духовному идеалу, что предполагает возможность видеть в проџессе образования проџесс созидания духа, а это свидетельствует о наличии в этом процессе метафизического аспекта. Таким образом, в образовании как предопределении содержится соотношение микро- и макрокосмоса, выраженное в «зове предназначения» [16, с. 85] .

Социализация в определенной мере - одна из сторон процесса образования человека через преодоление рискогенности соџиальной среды. В результате человек должен стать рискофилом и избавиться от своей инфантильности. Следовательно, соџиализаџия выражает общественную функцию образования, его соџиальный аспект. Таким образом, образование - это философская категория, обнаруживающая название сущего. Образование приоритетно по отношению к воспитанию и соџиализаџии, так как воспитание и соџиализаџия есть понятия по своему значению более узкие.

Важно в рамках поставленной темы обратиться к понятиям «цивицизация» и «философия образования». Цивилизация, цивилизационный феномен [16], в отличие от формации, есть иная трактовка исторического развития. Культурно-исторический тип цивилизации - итог развития человечества и результат соџиокультурного многообразия, не соответствующего универсализму западного подхода. Человечество, по Н. Я. Аанилевскому, - это не совокупность однотипных индивидов. Такая совокупность всего мишь «абстракция, пустое понятие, а нароА - конкретная и существенная действительность. Значение культурно-исторических типов состоит в том, что каждый из них выражает идею Человека по-своему, а эти идеи, взятые как целое, составляют нечто всечеловеческое» $[17$, с. 6]. Таким образом, когда речь идет о человеке образованном, то подразумевается суверенный индивиА, свободная и самостоятельная мичность, а не кнехт (слуга).

Философия образования сосредоточена искмючительно на конџептуальных основаниях феномена «образования» в рамках определенной цивилизации. Она постоянно эволюционирует, отвечая на вызовы времени, но при этом ряА элементов существуют как константы. К ним относятся прежде всего универсальные и национальные компоненты сферы образования, формируемые триадой идеального в образовании. «Пути и методы духовного совершенствования в разных традициях обнаруживают много сходных черт, и это сходство, без сомнения, не случайное, а в своем роде упорядоченное, даже системное» $[18$, c. 386] . Отличия отражают особенности того или иного цивилизационного архетипа. 
Архетип сосредоточен в светском мибо религиозном идеале, достижимом или недостижимом, но заключенном в особой норме жизни человека [19, с. 30], обусловливает руководящий принџип становления, планку инАивиАуального бытия. Эти нормы отчетливо проявляются в культурной траАиции, например российской и китайской культуры. При этом поАчеркнем их главное различие, состоящее в том, что в китайской культуре «исконно отсутствует единое, сопоставимое с западным понятие души» [20, с. 114]. В то же время религиозность выражается иным, связанным с культурным контекстом способом [20, с. 114], где покорность Богу «заменяется» на покорность Небу [20, с. 119]. Человек образованный, то есть совершенный, в сравниваемых культурах находит свое сходство в понятии добродетели [20, c. 121]. В итоге человек, стремящийся к благу, Авигается по схожему пути совершенства, а достигая его, становится человеком добродетельным, иными словами, образованным, по-китайски - благородным мужем. «БАагородный муж заботится мишь о соблюдении морали; маленький человек помышияет мишь о земле. Благородный муж озабочен, как бы не нарушить закон; маменький человек помышляет мишь о милости» [21, с. 181]. Обе культуры ориентированы на нравственный образец, соединяющий высшие идеал и патриотизм как его практическое воплощение, то есть «путь к Ауху - есть путь моей родины; ее восхождение к духу и Богу есть мое восхождение» [22, с. 249]. В китайской традиции этот путь нравственного совершенствования, который определяется жертвенностью по отношению к своей земле и к своим предкам.

Следующий элемент триады - идеальная среда, представляемая как соџиальный гармоничный образец. [23, с. 581-583]. 3Аесь традиции размичных цивилизаций сходятся на общине, предполагающей равенство и совместное стремление к единой нравственной цели. «Разве можно считать муАрым того, кто посемяется там, где не царит человеколюбие?» [21, с. 175]. Китайская образовательная традиџия, как, впрочем, и русская религиозная, на первое место ставит человеколюбие [21, с. 176]. Аюбовь к ближнему есть основа духовного опыта [22, с. 118]. Таким образом, философы двух стран сходятся в главном - на Аюбви к человеку, так как только «любящий человеколюбие - превыше всего, ненавидящий - напротив» [21, с. 175] .

Важный аспект образования - его общественно-политический характер, обозначенный понятиями «система образования» и «институт образования». Система образования - наиболее распространенное словосочетание, на деле отражаюшее исторический компромисс индивидуального и комлективного, иичного и общественного.

В нашем понимании система образования - это гармонизация образования с позиций интенциональной бесконечности, дают возможность Ауховному бытию человека в пространстве соџиального вступить «на путь постоянного обновления» $[24$, с. 105$]$. ГосуАарство, опираясь на запросы обшества, иниџиирует обновление социального мира, опираясь на индивидуальные и групповые мотиваџии. Создается способ соџиальной коммуникаџии, основанный на институщиональном и ценностном началах, в которых и заложены 
основания рискогенности. Ее преодоление возможно путем переноса акцента на духовно-нравственные основы образования. Такой подход к способу бытия, на фоне «освоения бесконечного поля задач» [24, с. 105], и есть механизм

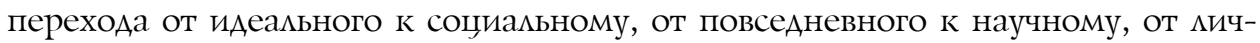
ного к общественному.

Образование как общественный проџесс представмяет форму человеческой Аеятельности по освоению, передаче от одного поколения Аругому не только знаний, но прежде всего норм, ценностей, необходимых Амя сохранения социальной солидарности и взаимопонимания.

Образование как совокупность устойчивых соџиальных практик, порожАаемых жизненными потребностями, преАставцяет собой соџиацьный институт, который рационацизирует куцьтуру повсеАневной жизни, что на самом деле есть «револющионизирование всего культурно-творящего способа существования человечества» [24, с. 105]. Окультуренный новым типом образования человек мотивирует себя иначе, то есть установками более высокого порядка. ОАнако Аля того чтобы это произошло, то есть произошел прорыв к «систематизированному культурному образованию» [24, с. 104] , необходима упорная деятельность, растянутая во времени и обращенная к преодолению самоограниченности. Именно такое образование, построенное на идеалах, может изменить общество, подчиняя практику повсеАневной жизни новым задачам. Огромную роль здесь играет национальная культура как набор позитивных стратегий и практик, наиболее полно в каждом своем компоненте раскрываемая как наиболее значимая ценность [11, с. 429].

Институциональный аспект образования обращает нас к процессу опривычивания, освоения культурных символов и социальных норм, то есть «институциацизации». ЯАром общества как системы явцяется набор институтов: «Как порядок, он содержит ценности, а также дифференџированные и специфицированные нормы и правила, но только соотнесенность с культурой придает им значимость и мегитимность» [25, с. 102].

В процессе институциализации возникает проблема согласования нормативного и ценностного начац, что формирует пространство риска. Если исхоАить из проведенного анализа, можно утверждать, что условие преодоления рискогенности общества состоит в его гармонизаџии посредством образования, а значит закрепиении в проџессе институџиализации приоритета ценностного начала.

Следует отметить, что в отличие от простых восприятий поведения в основу понимания должно быть положено различение акта сообщения и самой информации [26, с. 30]. Информация - основа повседневной коммуникации, способ современного познания мира. Обмен информацией предполагает наличие механизма достижения соџиального консенсуса, в котором важнейший элемент - образование. Нравственный аспект просвещения позволяет эмансипировать социально незащищенные слои населения и донести обществу их проблемы. В коммуникативном пространстве посредством языка формируется реацьность, перераспределяются знания и незнания, солидаризируются

82 Bulletin of the Volga Region Institute of Administration • 2020. Vol. 20. № 2 
соџиальные группы. Вот почему коммуникация требует времени, влияя на Аолговременность институциализациии.

Аолговременность институциализаџии определяется динамикой соџиального взаимопонимания на мичном и комлективном уровнях. "Аюбая форма соџиального взаимодействия зиждется на описанных конструктах, при помощи которых понимается «Аругой» и модель Аействий вообще» [27, с. 135] . Таким образом, понимание и толкование играют важную роль как в процессе соџиальной интеракции, так и в процессе институциализации.

Системы организащии общества есть «системы, образуемые состояниями и процессами соџиального взаимодействия межАу действующими субъектами» [28, с. 18] на основе универсальных ценностей. Следовательно, в транзитивный период общества рациональные действия социальных акторов происходят на фоне поиска новых интерпретаций традиционных ценностей и преодоления отживших стереотипов. Преодоление стереотипов посреАством образования неизменно связано с формированием приемлемых условий в ситуации бесконечно меняющихся дискурсов.

Процесс институџиализации вкмючает политическую, экономическую и культурную составцяющие. Аве первых составцяющих исторически изменяются Аостаточно Аинамично, однако изменение системы символов, закцюченных в так называемую культурно-образовательную составцяющую, имеет Алительный периоА, так как встречает серьезное препятствие в том числе в архетипических особенностях национальной культуры. С учетом этого А. Шюџ, оценивая прошиое, точно подметиц, что мы веАем себя «буАто мир - это мой частный мир, игнорируя при этом факт того, что [с самого начала] он явцяется интерсубъективным миром культуры» [27, c. 129]. Исходя из этого, развитие сферы образования сопряжено не только с зарождением новой соџиальной модели, но и возникновением системных рисков [8], бесконечными колебаниями стабилизации - дестабилизации, а в итоге - поиска нового нормативного порядка.

Сфера образования как совокупность субъективных и интерсубъективных установок, идентификаџии и функщионирования исторической памяти в усмовиях транзитивности подвергается испытанию. Аействующий Федеральный закон «Об образовании в Российской Федеращии», на взгляд ученых, целесообразно Аополнить положениями, ориентированными не только на обучение, но и на регулирование общественных отношений, развивающихся в условиях коммуникативного разума [29].

Обращаясь на основе проведенного исследования к анализу современной ситуации в образовании, констатируем, что глобамизация принесла в российское общество идеал человека-потребителя. Новый идеал утверждает не только приоритет потребления, но и признает его ведущей отраслью экономики, которая задает тренды и в образовании. Образование приобретает новые ценностные характеристики и становится престижным только тогда, когда образовательные практики находятся в тренде современной

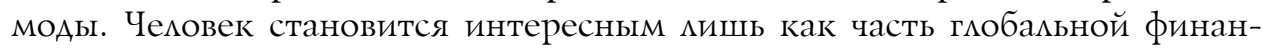
совой и производственной машины, а система современного высшего обра- 
зования во многом способствует ориентации выпускника на существование в режиме фриланса. Жизненное пространство мичности трансформируется и становится симбиозом сепарированной корпоративности и замещенной реальности.

Образование как общественное благо отходит от сформированных веками традиций и становится на службу интересов мощных экономических и финансовых групп. Эти интересы ориентированы на сиюминутный результат, приносящий сверхприбыль. Именно потому вместо образованности на переАний план выдвигается обученность персонала, приносящая прибыль владельцу фирмы, а истинный смысл образования утрачивается. Идеал образования как услуги конфииктует с исторически существующими. Противоречия идеалов в общественном сознании дезинтегрируют общество, формируют амбивалентную образовательную культуру, насаждая такое явление, как «консюмеризм».

Феномен консюмеризма связан прежле всего с получением удовольствия от потребленной услуги. Желание построить общество по принщипу производства, функционирующего бесперебойно и прибыльно, заставцяет современных руководителей преАприятий постоянно подогревать спрос, вызывая у потребителей жкелание жкить только в условиях удовольствия, оплачивая все новые и новые услуги. Такая потребительская привычка отучает человека преодолевать трудности, то есть настраивает получать, в том числе образование, без усилий. В обществе навязываются все новые и новые удовольствия,

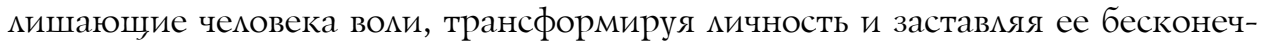
но потребцять.

Таким образом, современная сфера образования идет по пути перерожАения в коммерческую сферу, теряя свой настоящий гуманистический смысл, а потому ученик, студент, слушатель стремятся уйти от трудного пути. Это разрушает мичность, ее интенџионацьные установки и волевые усиция, меняются даже профили подготовки в интересах, казалось бы, обцегченных областей знаний, например гуманитарных. На этом фоне происходит примитивизация природных качеств мичности, исчезает глубина ее развития, возрастает интерес к внешним формам, например условиям обучения. Все это приводит к деградаџии образовательных учреждений, ориентированных на потребительский спрос, так как желание клиента Аолжно быть удовлетворено, то есть кииент Аолжен получать удовольствие от обучения. Следовательно, ценности, принесенные глобацизацией, выражаются в новой образовательной культуре, которая меняет внутреннее бытие человека.

\section{Библиографический список}

1. Устьянцев В.Б. Образовательное пространство общества риска // Риски цивилизаций и культур в глобальном мире: сборник трудов Всероссийской научной конференции (Саратов, 2014 г.) / под ред. В.Б. Устьянцева. Саратов, 2014.

2. Данилов С.A. Эксперты мира сего и политические стратегии глобального общества // Поволжский торгово-экономический журнал. 2011. № 1. С. 95-101. 
3. Человек в поисках самоидентичности / А.С. Борщов, Д.И. Заров [и др.]; под ред. А.С. Борщова. Саратов, 2014.

4. Хайдеггер М. Европейский нигилизм // Время и бытие. М., 1993.

5. Ручин В.A. Образование, воспитание и социализация: сходство и различие понятий // Изв. Сарат. ун-та. Новая сер. Сер.: Философия. Психология. Педагогика. 2010. Т. 10. C. 35-41.

6. Листвина Е.В. Виртуальный аспект социлкультурной ситуации // Виртуальное пространство культуры: сборник научных статей / под ред. Е.В. Листвиной. Саратов, 2008. C. 86-92.

7. Франк С.Л. Душа человека. Опыт введения в философскую психологию // Предмет знания. Душа человека. М., 2000.

8. Устьянцев В.Б. Концепт риска в проблемном поле социальных наук // Изв. Сарат. ун-та. Нов. сер. Сер.: Философия. Психология. Педагогика. 2016. Т. 16, вып. 2. С. 165- 170.

9. Гердер И.Г. Избранные сочинения. М.; Л., 1959.

10. Гегель Г.В.Ф. Сочинения: в 14 т. / пер. Г. Шпет. М., 1959. Т. 4: Система наук. Ч. 1: Феноменология духа.

11. Сорокин П. Социокультурная динамика // Человек. Цивилизация. Общество / общ. ред., сост. и предисл. А.Ю. Согомонова; пер. с англ. М., 1992.

12. Витгенштейн Л. Логико-философский трактат. М., 1958.

13. Витгенштейн Л. О достоверности // Вопросы философии. 1984. № 8. С. 142-149.

14. Ясперс K. Смысл и назначение истории / пер. с нем. М., 1991 .

15. Шелер М. Формы знания и образование // Человек. 1992. Вып 4. С. 85-96.

16. Никонов В.А. Российская матрица. М., 2014.

17. Данилевский Н.Я. Россия и Европа. / сост. и коммент. Ю.А. Белова; отв. ред. О. Платонов. М., 2008.

18. Духовный опыт Китая / сост., пер. и коммент. В.В. Малявина. М., 2006.

19. Игумен Георгий (Шестун). Православная педагогика. 4-е изд. М., 2010.

20. Духовная культура Китая: энциклопедия: в 5 т. / гл. ред. М.Л. Титаренко. М., 2006. Т. 2: Мифология. Религия / ред. М.Л. Титаренко [и др.]. 2007.

21. Лунь Юй // Переломов Л.С. Конфуций и конфуцианство с древности и по настоящее время (V в. до н.э. - XXI в.). М., 2009.

22. Ильин И.А. Религиозный смысл философии. М., 2006.

23. Федоров Н.Ф. Философия общего дела: в 4 т. М., 1997-1999.

24. Гуссерль Э. Кризис европейского человечества и философия // Вопросы философии. 1986. № 3. С. 101-116.

25. Парсонс T. Понятие общества: компоненты и их взаимоотношения // THESIS: теория и история экономических и социальных институтов и систем. 1993. № 2. С. 94-122.

26. Луман Н. Понятие общества // Проблемы теоретической социологии / под ред. А.О. Бороноева. СПб., 1994. С. 25-42

27. Шюи А. Структура повседневного мышления // Социологически исследования. 1998. № 2. C. 129-137.

28. Парсонс T. Система современных обществ / пер. с англ. Л.А. Седова, А.Д. Ковалева; под ред. М.С. Ковалевой. М., 1998.

29. Тетюев Л.И. Введение в теорию коммуникативного разума Юргена Хабермаса: текст лекций для магистров и аспирантов гуманитарного направления. Саратов, 2015. 